\title{
Test Anxiety, Depression and Academic Performance: Assessment and Management Using Relaxation and Cognitive Restructuring Techniques
}

\author{
Esther F. Akinsola, Augustina Dubem Nwajei \\ Department of Psychology, Faculty of Social Sciences, University of Lagos, Lagos, Nigeria \\ Email: foluk6@yahoo.com,nwajeidubem@yahoo.co.uk \\ Received April 15 $5^{\text {th }}, 2013$; revised May $17^{\text {th }}, 2013$; accepted June $14^{\text {th }}, 2013$
}

\begin{abstract}
Copyright (c) 2013 Esther F. Akinsola, Augustina Dubem Nwajei. This is an open access article distributed under the Creative Commons Attribution License, which permits unrestricted use, distribution, and reproduction in any medium, provided the original work is properly cited.
\end{abstract}

\begin{abstract}
Examination as a word evokes varying degrees of anxiety in students depending on the importance of the examination, perceived difficulty level of the subject, and degree of preparedness for the examination. A perceived difficult subject would elicit higher anxiety levels, and test anxiety as a psychological condition can adversely affect people in every field of life (Cohen, 2004), and especially it adversely affects students who face different examinations. The suspicion is that test anxiety may not exist alone but co-exist with other forms of psychological distress such as depression, and psychological intervention such as cognitive therapy is expected to reduce students' anxieties and any other psychological distress and consequently improve their academic performance. In an attempt to verify our suspicion and confirm the expectation, 420 senior secondary school students made up of 210 males and 210 females aged between 13 and 19 years responded to test anxiety, trait anxiety, and depressive symptoms inventories. 72 of the students whose test anxiety scores were higher than the group's average score were divided into three groups and treated under three conditions of "no treatment", "relaxation treatment alone", and combined "relaxation and cognitive restructuring treatment". Results obtained show that test anxiety, trait anxiety, and depression co-exist and are positively related, and they are negatively related to academic performance. In addition the combination of relaxation and cognitive restructuring treatment reduced anxiety and depression better than relaxation treatment alone or no treatment and improved test performance of the students much more than any of the other two conditions. The findings thus confirm the effectiveness and efficacy of cognitive therapy in managing anxiety and depression and improving academic performance, and when combined with relaxation technique, the combination optimizes academic performance.
\end{abstract}

Keywords: Test Anxiety; Academic Performance; Relaxation \& Cognitive Restructuring

\section{Introduction}

"We live in a test conscious and test giving culture in which the lives of people are in part determined by their test performance" (Sarason, Davidson, \& Lighthall, 1960: p. 26). As it was then in 1960 even so it is now in 2013. Tests and examinations at every educational level have become a global and very powerful strategy for decision making about people at all ages and all strata. All over the world people are evaluated in terms of their skills, abilities and achievements and such evaluations are determined by their test performance (Rana \& Mahmood, 2010).

One of the challenges in the educational sector is examination problem. The word "examination" though familiar to all students, it evokes varying degrees of anxiety in them depending on the importance attached to the examination and their level of preparedness for the examination. Furthermore the severity of such anxiety increases as the examination approaches, and peaks on the night preceding the examination (Tooranposhti, 2011).

\section{Test Anxiety and Academic Performance}

Test anxiety is a psychological condition in which people experience extreme distress and anxiety in testing situations. While many people experience some degree of stress and anxiety before and during examinations, test anxiety can actually impair learning and hurt test performance. Test anxiety is an overwhelming feeling of disturbance and distress among students globally and can be a devastating problem for them because it may impair their performance and their well being later in life in the long run (Farooqi, Ghani, \& Spielberger, 2012; Rafiq, Ghazai, \& Farooqi, 2007). According to (Cohen, 2004), test anxiety can adversely affect people in every field of life whenever and wherever people of all ages and strata have to be evaluated, assessed and graded in terms of their abilities, achievements or interests.

Zeidner (1998) outlined three components of test anxiety to be cognitive, affective, and behavioural. The cognitive component involves worry or negative thoughts, depreciating self statements that occur during assessments and performance in- 
hibiting difficulties that may arise from anxiety (e.g. problem in recalling facts, difficulty in reading and understanding questions). The affective component includes the person's appraisal of his/her physiological state such as tension, tight muscles and trembling. The behaviour component includes poor study skills, avoidance and procrastination of work.

Zeidner (1998) cited Carver \& Scheier (1984) as arguing that test anxious persons are likely to have strong and chronic doubts about either producing adequate performance on examinations, being evaluated favourably by significant others, or being able to control their feelings so that they would not be overwhelmed by them.

Speilberger \& Vagg (1995) regarded test anxiety as a situation specific or state anxiety which is a temporary emotional state. This according to Speilberger, Gorsuch, \& Lushene (1970) is different from trait anxiety which is a constant personality characteristic. According to Speilberger \& Vagg (1995), test anxious individuals are more prone to react with excessive anxiety such as worry, negative thoughts, nervousness and physiological arousal across testing situations. This proneness predisposes them to experiencing more intense levels of state anxiety which is considered as the emotional component of test anxiety in evaluative situations. The high level of state anxiety among test anxious people activates worry conditions stored up in memory and these conditions interfere with test performance (Zeidner, 1998). A positive relationship between trait and test anxiety is therefore expected.

\section{Hebb's Theory of Arousal (1972)}

Hebb's theory which is useful in explaining the relationship between test anxiety and academic performance was an adaptation of Yerke's Dodson law (1908). The theory states that human beings seek out an optimal level of arousal such that too low arousal brings about boredom while too high arousal leads to stress. This theory predicts a U-shaped function between arousal (anxiety) and performance. It assumes that both low and high levels of arousal (anxiety) produce minimum performance while a moderate level results in maximum performance. Arousal can be high at times of excitement or panic.

Numerous studies have been carried out to determine the relationship between test anxiety and performance. In one study, Cassady and Johnson (2002) found that cognitive test anxiety exerts a significant stable and negative impact on students' academic performance. In another study, Kassim, Hanafi, \& Hancock (2008) investigated the consequences of test anxiety on academic performance among university students, and found test anxiety to be negatively related to academic performance. Hancock (2001) studied the effects of students' test anxiety and teacher's evaluation practices on students' achievement and motivation at post secondary level and found that students with high anxiety level performed poorly and were less motivated to learn. Ndirangu, Muola, Kithuka, \& Nassluma (2009) in their own study on the relationship between test anxiety and academic performance found that secondary school students exhibited higher anxiety levels before the examination in all subjects. Chapell, Blanding, Takahashi, Silverstein, Newman, Gubi, and McCann (2005) explored the relationship between test anxiety and academic performance using graduate and undergraduate students as participants. They found a negative relationship between test anxiety and academic achievement. In a more recent study, Rana \& Mahmood (2010) investigated the relationship between test anxiety and academic achievement. They found a negative relationship between test anxiety and achievement. They also found that a cognitive factor (worry) contributes more in test anxiety than affective (emotional) factor. In another study, Marzieh Gholami tooranposhti (2011) examined the effect of self regulation education on test anxiety, academic achievement and meta-cognition and found that self regulation education reduces test anxiety. Farooqi, Ghanl, \& Spielberger (2012) in their own study examined gender differences in test anxiety and academic performance and found that female medical students reported higher test anxiety levels than male medical students. They also found a negative relationship between test anxiety and academic performance.

\section{Depression and Academic Performance}

Depression as a mood disorder affects a person's ability to perform life activities including academic performance (Hysenbegasi, Hass, \& Rowland, 2005). It is common for people who suffer from depression to engage in self blame, experience confusion and a feeling of hopelessness. The major components of depression are loss of interest in activities that were once found pleasurable and a depressed mood (Schwartz \& Schwartz, 1993). It has been found that loss of interest aspect of depression is associated with lower grade point averages and students who suffer from both anxiety and depression had poor academic performance (Eisenberg, 2009).

\section{Beck's Cognitive Behavioural Theory of Depression (1976)}

Beck proposed that negative automatic thoughts generated by dysfunctional beliefs were the cause of depressive symptoms. He hypothesized that depressed patients have a negative view of themselves, their environment and their future. Depressives distort reality by harbouring negative feelings about anything and everything and they develop thoughts of worthlessness and inferiority (Papalia \& Olds, 1988; Schwartz \& Schwartz, 1993). Beck maintained that depression-prone individuals are more likely to notice and remember situations in which they have failed or did not live up to some personal standard while ignoring successful situations. As such they maintain their negative sense of self leading to depression (McGinn, 2000).

Some groups of people have been identified as having higher chances of developing depression. Such people include the poor, the unemployed, women and students (Wetzel, 1984). Some studies have focused on adolescent's depression while some focused on the relationship between depression and academic performance.

In one of such studies on adolescent's depression, Moilanen (1995) found that the student's depression was often associated with dysfunctional beliefs and negative future attitudes. She suggested that the cognitive theory has reasonable validity for describing the systems of depression for non-referred adolescents. In an earlier study (Moilanen, 1993) evaluated depression in college students and found that students' current depressive states were consistently related to their negative processing of personal information (Moilanen, 1993: p. 345). She found that the students' cognitive thoughts were affecting them and making them develop symptoms of depression and thereby suggested a cognitive treatment for students' depression. Studies that focused on the relationship between depression and aca- 
demic performance include those carried out by Hysenbegasi et al. (2005), DeRoma, Leach, \& Leverett (2009), Busari (2012), and Owens, Stevenson, Hadwin, \& Morgate (2012).

Hysenbegasi et al. (2005), studied the impact of depression on the academic productivity of university students and found that depressed students reported a pattern of increasing interference of depression symptoms with academic performance peaking in the month of diagnosis and decreasing thereafter with the lowest levels reported in 4 to 6 months post diagnosis. DeRoma et al. (2009) in their own study examined the association between self reported depressive symptomology and college academic performance. They found a significant and negative relationship between depression and academic performance. In addition they found that students who reported moderate levels of depressive symptoms demonstrated lower performance within academic environments when compared to those with normal and minimal levels of depression. In another study, Busari (2012) evaluated the relationship between gender, age depression and academic performance among adolescents. She found that depression and academic performance were significantly and negatively correlated, age and academic performance were significantly and positively correlated and females performed significantly better than males. Owens et al. (2012) in their own study investigated the relationship between negative affect, worry, working memory and academic performance. They found that higher levels of anxiety and depression were associated with lower academic performance and concluded that academic performance is reduced in young people with high levels of anxiety or depression as a function of increased test-specific worry that impinges on working memory central executive processes. If worry and negative thoughts are the cognitive component of anxiety (Zeidner, 1998; Speilberger \& Vagg, 1995), and negative automatic thoughts generated by dysfunctional beliefs (cognitive components) are the cause of depressive symptoms (Beck, 1976, 1983) then an appropriate treatment for anxiety and depression must involve cognitive therapy.

\section{Beck's Cognitive Behaviour Therapy-Cognitive Restructuring}

In treating depression Beck emphasized understanding and changing the patient's core beliefs. By restructuring destructive thinking he believed that positive changes could be brought in the patient (Loveleena Rajeev, 2013). The therapist is expected to involve the patient in setting realistic goals and taking responsibilities for action and thought. By changing thought and perception a change in behaviour and emotional responses can result. The patient is educated on the concept of faulty thinking and new ways and ideas are generated to develop a positive outlook of self experiences and environment (Loveleena Rajeev, 2013). In therapy the patient learns to apply cognitive restructuring techniques so that negatively distorted thoughts underlying depression can be corrected and replaced with more logical and adaptive thinking. Many studies have been conducted to ascertain the efficacy of cognitive therapy for depression. In one of such studies, Rush, Beck, Kovacs, \& Hollon (1977) compared the use of therapy with the use of tricyclic antidepressant therapy (pharmacotherapy) using patients suffering from clinical depression. They found that cognitive therapy was more effective than tricyclic anti-depressant therapy and relapse rates were lower among patients who received cognitive ther- apy.

In another study, Blackburn, Bishop, Glen, Whalley, \& Christie (1981) investigated the efficacy of cognitive therapy and pharmacotherapy each alone and in combination in the treatment of depression. They found that cognitive therapy was superior to drug treatment in general practice, the antidepressant drug group did less well in both hospital and general practice, and the combination treatment was superior to drug treatment. Some other researches that involve meta-analyses of the effects of cognitive therapy in treating depression (e.g. Dobson, 1989; Wampold, Mnami, Baskin, \& Callen Tiemey, 2002; Gloaguen, Cottraux, Cucherat, \& Blackburn, 1998) found that cognitive therapy was superior to no treatment or placebo; cognitive therapy is as effective as interpersonal or brief psychodynamic therapy in managing depression. They also found that cognitive therapy is as effective and even more effective than pharmacotherapy in managing mild to moderate unipolar depression.

In a review of studies on cognitive therapy and depression, Stuart J. Rupke, David Blecke, \& Marjorie Renfrow (2006) confirmed that cognitive therapy is an effective treatment for depression and is as effective as antidepressants or interpersonal or psychodynamic therapy. Their review also confirmed the effectiveness of the combination of cognitive therapy with other forms of therapy. They also affirmed that some studies have shown that cognitive therapy is effective for managing adolescents with depression. Some studies have also shown that relaxation techniques can be used to manage some mental health conditions including anxiety and depression. In the review of studies on anxiety, e.g. Sultanoff \& Zalaquett (2000) found that drug and behaviour treatments have similar shortterm effect but behavioural treatment had better long-term effects than drug treatment of anxiety disorders. In another study Biabangard (2003) compared the effectiveness of Lazarus multimodal therapy, Ellis Rational Emotive therapy, relaxation and placebo in decreasing students' test anxiety. The findings revealed that the four therapeutic methods were more effective in reducing anxiety than the control group. Lazarus multimodal therapy was found to be more effective in reducing anxiety than relaxation, placebo and control groups.

Based on the above reviewed literature it is reasonable to expect a relationship between trait anxiety and test anxiety, test anxiety and depression, gender and test anxiety. It is equally reasonable to propose that cognitive therapy and relaxation techniques would be effective in reducing anxiety and depression in secondary school adolescents and consequently improving their performance. This study attempted to verify this expectation with the following hypotheses as guides

\section{Hypotheses}

1) There would be a positive relationship between trait anxiety, test anxiety and depression.

2) Female participants would report higher levels of test anxiety than males.

3) Cognitive restructuring and relaxation techniques would be effective in reducing anxiety and depression and improving test performance in the students such that post treatment performance would be better than pre-treatment performance in mathematics test.

4) Students who received cognitive restructuring and deep breathing relaxation therapy would perform better than those 
who received only deep breathing relaxation therapy and the control group that received no therapy.

\section{Method}

\section{Participants}

420 senior secondary school students consisting of 210 males and 210 females aged between 13 and 19 years participated in the assessment phase of the study. The participants were nonclinical and non referred students randomly selected from classes I, II and III of three different secondary schools. 140 students were selected from each class respectively. Out of the 420 students that participated in the assessment phase 72 of them whose test anxiety scores were higher than the sample's mean score took part in the treatment phase.

\section{Instruments}

The instruments administered to the students were state-trait anxiety inventory (STAI), test anxiety inventory (TAI), symptoms distress checklist (SCL-90) and mathematics test.

\section{State-Trait Anxiety Inventory (STAI Y-2)}

This inventory developed by (Spielberger, 1970) measures general anxiety. It consists of two forms Y-1 and Y-2. Y-1 measures state anxiety which is the present state anxiety level of the individual while Y-2 measures trait anxiety which is the relatively stable predisposition of a person to being anxious. The form Y-2 was used in this study to measure the students' predisposition to being anxious and the test anxiety inventory was used to measure their situational anxiety level. Form Y-2 consists of 20 items and the responses to them vary from "almost never" to "almost always" with a minimum score of 20 and maximum of 80 . Spielberger provided reliability coefficients of 0.90 and 0.91 for the two forms. For the present sample the reliability coefficients for Y-2 are: Cronbach alpha = 0.80 , split half $=0.72$ and one week test retest $=0.85$.

\section{Test Anxiety Inventory (TAI)}

This inventory also developed by (Spielberger, 1980) measures anxiety proneness to examinations and evaluative situations. The inventory consists of 20 items that assesses two components of test anxiety namely worry (W) and emotionality (E). Responses to the items vary from "almost never" to "almost always" with a minimum score of 20 and maximum of 80 . Worry (W) was defined as excessive pre-occupation and concern about the outcome of examinations, especially the consequences of failure. Worry is a cognitive component of test anxiety (Zeidner, 1998). Emotionality was defined as an individual's behavioural reactions and feelings aroused by test situations. The test anxiety composite score was defined as the overall cognitive, affective and behavioural reactions to examination situations. Spielberger (1980) reported reliability coefficient of 0.08 for the inventory. The reliability coefficients for the present sample are: Cronbach alpha $=0.77$, split half $=0.78$, and one week interval test retest $=0.87$.

\section{Symptoms Distress Checklist (SCL-90)}

This checklist was developed by Derogatis, Lipman, \& Covi (1977). It consists of 10 subscales that measure 10 categories of symptoms associated with stress. Subscale D designed to assess depression was used to determine the depression status of the students. This subscale consists of 13 items and the responses to them vary from "not at all" to "extremely" with the minimum score being zero and the maximum 52. Derogates et al. reported Cronbach alpha and test retest reliability coefficients of 0.90 and 0.90 for the subscale respectively. For the present sample the reliability coefficients are: Cronbach alpha $=0.70$, split half $=0.63$, one week test retest $=0.88$

\section{Mathematics Test}

The mathematics test was constructed by the researchers in line with the taught syllabus of each class and using the contents in the relevant sections of the mathematics textbooks of their respective classes. The test contains multiple choice answer questions considered appropriate for their respective classes. The mathematics test was given to the 72 students in the treatment groups. Mathematics examination has the potential of evoking high level of anxiety in secondary school students. This is because for them to go beyond secondary school level to tertiary institutions a minimum of grade $\mathrm{C}$ (Credit) in Mathematics and English language are required and many students don't like mathematics because of the calculations involved. As such it was expected that the students would perform poorly in the mathematics test and the application of cognitive therapy and relaxation techniques would reduce their anxiety and depression levels and consequently improve their performance in the test when taken again after therapy.

\section{Procedure}

In the assessment stage the three instruments measuring trait anxiety, test anxiety and depression were administered to the 420 students to determine the base line for selecting those who would participate in the treatment phase. It was ensured that the students were comfortably seated in a well ventilated and bright room before the administration of the tests.

In the treatment phase 72 students whose scores on test anxiety were above the sample's mean score were randomly selected and divided into three groups of 24 participants per group and 8 participants from each of the three classes in each group. Each group was made up of 15 males and 9 females.

\section{Treatment}

The treatment involved the use of deep breathing as a relaxation technique and cognitive restructuring as cognitive therapy technique. The first group (Group 1) served as the control group and did not receive any treatment. The second group (Group 2) served as the experimental group I and received only deep breathing relaxation as treatment. The third group (Group 3) served as experimental group II and received both deep breathing relaxation and cognitive restructuring as treatment. The experimental group I received (8) ten minutes sessions of deep breathing relaxation while the experimental group II received (8) ten minutes sessions of deep breathing and (6) twenty minutes sessions of cognitive restructuring. In the course of the cognitive therapy the students were encouraged to examine their attitudes toward examinations and construct positive self affirmations by creating personal words and phrases that carry the meaning of success in examinations to describe themselves. They were also encouraged to visualize themselves 
succeeding and rehearsing forthcoming examination situations. After the treatment sessions parallel forms of the mathematics tests were given to three groups under the same conditions as the pre-treatment

\section{Results}

\section{Hypothesis 1}

There would be a positive relationship between trait anxiety, test anxiety and depression.

The mean scores of the students in the three measures recorded in Table 1 above represent the norms for the three scales and indicate that the students' proneness to anxiety is high and thinking about approaching test can aggravate their anxiety levels. The participants' mean scores are: $42.58,42.43$, \& 14.39 for trait anxiety, test anxiety and depression respectively. In Table 2 the correlation coefficients of $0.422,0.319$ and 0.284 indicate positive and significant relationships between trait anxiety, test anxiety and depression. The implication is that the higher the students' predisposition to anxiety the higher the test anxiety and depression they reported. These results lend support to the first hypothesis.

\section{Hypotheis 2}

Female participants would report higher levels of test anxiety than males.

Looking at Table 3 above the difference between the mean scores of males and females in test anxiety is not significant

Table 1.

Mean and Std. Dev of participants' scores on anxiety and depression measures.

\begin{tabular}{cccc}
\hline Measures & $\mathrm{N}$ & Mean & Std. Dev. \\
\hline Trait anxiety & 420 & 42.58 & 7.44 \\
Test anxiety & 420 & 42.43 & 8.83 \\
Depression & 420 & 14.39 & 7.59 \\
\hline
\end{tabular}

Table 2.

Correlation matrix of anxiety and depression variables.

\begin{tabular}{cccc}
\hline & Test anxiety & Trait anxiety & Depression \\
\hline Test anxiety & - & & \\
Trait anxiety & $0.422^{*}$ & - & \\
Depression & $0.319^{* *}$ & $0.284^{* *}$ & - \\
\hline
\end{tabular}

Table 3.

Mean and Std. Dev. of participants' scores on test anxiety according to gender.

\begin{tabular}{|c|c|c|c|c|c|c|c|c|}
\hline Variable & Group & $\mathrm{N}$ & Mean & $\begin{array}{l}\text { Std. } \\
\text { Dev. }\end{array}$ & $\mathrm{Df}$ & $\underset{t}{\text { Calculated }}$ & $\begin{array}{c}\text { Critical } \\
t\end{array}$ & $P$ \\
\hline \multirow[t]{2}{*}{$\begin{array}{c}\text { Test } \\
\text { Anxiety }\end{array}$} & Male & 210 & 42.71 & 8.86 & 418 & 0.65 & 1.98 & $P>0.05 \mathrm{NS}$ \\
\hline & Female & 210 & 42.15 & 8.81 & - & - & - & \\
\hline
\end{tabular}

indicating that males and females reported similar levels of test anxiety. The mean scores for males and females are 42.71 and 42.15 respectively. These results do not support hypothesis 2 .

\section{Hypothesis 3}

Cognitive restructuring and relaxation techniques would be effective in reducing anxiety and depression and improving test performance in the students such that post treatment performance would be better than pre-treatment performance in mathematics test.

From Table 4 it can be seen that groups I and group II that received relaxation alone and combined relaxation and cognitive restructuring performed significantly better after treatment than before treatment. This means that the treatment given reduced the anxiety and depression levels of the students and this reduction in turn led to their improved performance on the test. The mean scores on the test are: control group: 5.83 vs 6.08 ; relaxation only group: 5.87 vs 8.04 ; therapy combination group: 5.83 vs 9.45 . These results support the third hypothesis.

\section{Hypothesis 4}

Students who received cognitive restructuring and deep breathing relaxation therapy would perform better than those who received only deep breathing relaxation therapy and the control group that received no therapy.

A look at Table 5 above shows that the group that received the combination of relaxation and cognitive restructuring treatment had the highest test performance mean score followed by the group that received relaxation treatment alone. The control group had the least performance mean score. The mean scores for the test are: $6.08,8.04, \& 9.45$. These results indicate that the combined treatment reduced anxiety and depression in the students more than relaxation alone or no treatment and this made the students to perform best in the test. From Table 6 it is

Table 4.

Comparisons of participants' pre and post therapy test performance mean scores using " $\mathrm{t}$ " test statistic.

\begin{tabular}{|c|c|c|c|c|c|c|c|}
\hline & Group & $\mathrm{N}$ & Mean & Df & Cal t & Crit t & $P$ \\
\hline \multirow{2}{*}{ Control } & Before Therapy & 24 & 5.83 & \multirow{2}{*}{46} & \multirow{2}{*}{0.488} & \multirow{2}{*}{1.658} & \multirow{2}{*}{$P>0.05 \mathrm{NS}$} \\
\hline & After Therapy & 24 & 6.08 & & & & \\
\hline \multirow{2}{*}{ Group I } & Before Therapy & 24 & 5.87 & \multirow{2}{*}{46} & \multirow{2}{*}{4.735} & \multirow{2}{*}{1.658} & \multirow{2}{*}{$P<0.05$} \\
\hline & After Therapy & 24 & 8.04 & & & & \\
\hline \multirow{2}{*}{ Group II } & Before Therapy & 24 & 5.83 & \multirow{2}{*}{46} & \multirow{2}{*}{6.033} & \multirow{2}{*}{1.658} & \multirow{2}{*}{$P<0.05$} \\
\hline & After Therapy & 24 & 9.45 & & & & \\
\hline
\end{tabular}

Note: table $\mathrm{t}$ value is $1.658 \mathrm{P} \leq 0.05$.

Table 5.

Mean and Std. Dev. of participants' post therapy test performance scores according to groups.

\begin{tabular}{cccc}
\hline Groups & No & Means & Std. Deviation \\
\hline Control Group & 24 & 6.083 & 2.02 \\
Group I & 24 & 8.04 & 1.78 \\
Group II & 24 & 9.45 & 2.57 \\
\hline
\end{tabular}


Table 6.

Summary of analysis of variance of the groups' post therapy test performance scores.

\begin{tabular}{cccccc}
\hline Source & Sum of Squares & df & Mean Square & F & $P$ \\
\hline Between group & 137.86 & 2 & 68.93 & 14.92 & $P<0.05$ \\
Within group & 318.75 & 69 & 4.62 & \\
Total & 456.61 & 71 & & \\
\hline
\end{tabular}

Note: table value of $\mathrm{F}$ is $3.07 P<0.05$.

evident that the differences in the mean scores in Table 5 are significant with the value of $\mathrm{F}$ being $\mathrm{F}=14.92$, and $P<0.05$. These results lend support to hypothesis 4 .

\section{Discussion}

\section{Major Findings}

1) A positive and significant relationship was found between test anxiety, trait anxiety, and depression.

2) The test anxiety levels of males and females were not significantly different.

3) Deep breathing relaxation and cognitive restructuring techniques significantly reduced anxiety and depression in the students and significantly improved their post treatment test performance.

4) Students who received the combination of relaxation and cognitive restructuring had the best post treatment performance followed by the performance of those who received relaxation therapy alone. The control group that received no treatment had the least improvement in their performance.

Concerning test anxiety, a positive relationship exists between trait and test anxiety in such a way that as test anxiety increased, trait anxiety also increased. Students who suffer from test anxiety also reported suffering from depression thereby confirming depression as a correlate of test anxiety. When the anxiety levels of the students were reduced though therapy their performance in the test improved tremendously, suggesting a negative relationship between anxiety and test performance. This finding agrees with the findings of Kassim et al. (2008), Chapell et al. (2005), \& Farooqi et al. (2012), that found test anxiety to be negatively related to academic performance.

As the anxiety levels of the students reduced through therapy their depression levels also reduced and this facilitated improved performance. This finding confirms the negative relationship between depression and academic performance, and agrees with the findings of Busari (2012), \& Owen et al. (2012), who also found depression to be negatively and significantly related to academic performance. The fact that the students' performance improved significantly after relaxation and cognitive therapy affirms their efficacy in managing test anxiety and depression and improving test performance. Rush et al. (1977), Blackburn et al. (1981), \& Wampold et al. (2002) found cognitive therapy to be an effective therapy, and even superior to other forms of therapy, in managing clinical depression. The present findings further confirm its efficacy and effectiveness in managing both clinical and nonclinical depression and anxiety. The combined therapy that resulted in improved performance highlights the benefit of addressing the cognitive and emotional components of anxiety in therapy, as well as the added advantage of combining cognitive therapy with other forms of ther- apy to ensure maximum and enduring therapeutic benefits.

Ordinarily test anxiety in students may not degenerate to clinical levels, but the fact that excessive anxiety has been linked to poor academic performance (Mandler \& Sarason, 1952; Sarason, 1975; Owen et al., 2012), and examination being a global phenomenon, it is necessary for examination bodies and institutions to make provisions for intervention centres where students can be helped to reduce their test anxiety levels and optimize their performance.

\section{REFERENCES}

Beck, A.T. (1976). Cognitive therapy and the emotional disorders. New York: International University Press.

Beck, A.T. (1983). Cognitive therapy of depression: New perspectives. In P. J. Clayton, \& J. E. Barett (Eds.), Treatment of depression. Old controversies and new approaches (pp 265-284). New York: Raven Press.

Biabangard, E. (2003). Effectiveness of Lazarus multimodal therapy, Ellis rational emotional therapy and relaxation on decreasing students test anxiety. Iranian Journal of Psychiatry and Clinical Psychology, 8, 36-42.

Blackburn, I. M., Bishop, S., Glen, A. I., Whalley, L. J., \& Christie, J. E. (1981). The efficacy of cognitive therapy in depression: A treatment trial using cognitive therapy and pharmacotherapy, each alone and in combination. British Journal of psychiatry, 139, 181, 189.

Busari, A. O. (2012). Evaluating the relationship between gender age depression and academic performance among adolescents. Scholarly Journal of Education, 1, 6-12.

Cassady, J. C., \& Johnson, R. E. (2002) Cognitive test anxiety and academic performance. Contemporary educational Psychology, 27, 270295. http://www.idealibrary.comon

Chapell, M. S., Blanding, Z. B., Takahashi, M., Silverstein, M. E., Newman, B., Gubi, A., \& Mccann, N. (2005). Test anxiety and academic performance in undergraduate and graduate students. Journal of Educational Psychology, 97, 268-274. doi: $10.1037 / 0022-0663.97 .2 .268$

Cohen, A. (2004). Tests anxiety and its effect on the personality of students with learning disabilities.

http://www.thefreelibrary.com/test + anxiety + and + its + effect + on + the + personality+of+students+with+...a0122258760

Derogatis, L. R., Lipman, R. S., \& Covi, L. (1977) Manual for the symptoms distress checklist 90 (SCL-90). Baltimore: John Hopkins University School of Medicine, Clinical Psychometrics Research Unit.

DeRoma, V. M., Leach, J. B., \& Leverett, J. P. (2009) The relationship between depression and college academic performance. College Student Journal, 43, 325-334.

Dobson, K. S. (1989). A meta-analysis of the efficacy of cognitive therapy for depression. Journal of Consulting Clinical Psychology, 57, 414-419. doi:10.1037/0022-006X.57.3.414

Elsenberg, D. (2009). College students-Depression and academic performance. Depression Forums Web Page.

Farooqi, Y. N., Ghanl, R., \& Spielberger, C. D. (2012) Gender differences in test anxiety and academic performance of medical students. International Journal of Psychology and behavioural Sciences, 2, $38-43$.

Gloaguen, V., Cottraux, J., Cucherat, M., \& Blackburn, I. M. (1998). A meta-analysis of the effects of cognitive therapy in depressed patients. Journal of Affective Disorders, 49, 59-72. doi:10.1016/S0165-0327(97)00199-7

Hebb, D. O. (1972) Text book of psychology (3rd ed.). Philadelphia: Saunders.

Hysenbegasi, A., Hass, S. L., \& Rowland, C. R. (2005) The impact of depression on the academic productivity of university Students. Journal of Mental Health Policy Economic, 8, 145-151.

Kassim, M. A., Hanafi, R. M., \& Hancock, D. R. (2008). Test anxiety and its consequences on academics performance among university students. Advance in Psychology Research, 53, 75-95. 
www.books.Google.com.pk/book?

Loveleena Rejeev (2013). Aaron Beck's cognitive behaviour theory. Buzzle.com

Mandler, G., \& Sarason, I. G. (1952). A study of anxiety and learning, Journal of Abnormal and Social Psychology, 87, 166-173. doi: $10.1037 / \mathrm{h} 0062855$

McGinn, L. K. (2000). Cognitive behavioral therapy of depression: Theory, treatment and empirical status. Amenean Journal of Psychotherapy, 54, 254-260.

Moilanen, D. L. (1995). Validity of Beck's cognitive theory of depression with non-referred adolescents. Journal of Counselling and Development, 73, 438-442.

Moilanen, D. L. (1993). Depressive information processing among nonclinic, non-referred college students. Journal of Counselling Psychology, 40, 340-347. doi:10.1037/0022-0167.40.3.340

Ndirangu, G. W., Muola, J. M., Kithuka, M. R., \& Nassiuma, D. K. (2009). An investigation of the relationship between test anxiety and academic performance in secondary schools in Nyeri District, Kenya. Global Journal of educational Research, 8, 1-7.

Owens, M., Stevenson, J., Hadwin, J. A., \& Morgate, R. (2012). Anxiety and depression in academic performance. An exploration of the mediating factors of worry and working memory. School Psychology International. doi:10.1177/0143034311427433

Papalia, D. E., \& Olds, S. W. (1988). Psychology. New York: McGrawHill Book Company.

Rafiq, R., Ghazal, S., \& Farooqi, Y. N. (2007). Test anxiety in students: Semester vs annual system. Journal of Behavioural Sciences, 17, 7995.

Rana, R. A., \& Mahmood, N. (2010). The relationship between test anxiety and academic achievement. Bulletin of Education and Research, 32, 63-74.

Rush, A. J., Beck, A. T., Kovacs, M., \& Hollon, S. (1977). Comparative efficacy of cognitive therapy and pharmacotherapy in the treat- ment of depressed outpatients. Cognitive Therapy Research, 1, 17 37. doi:10.1007/BF01173502

Sarason, I. G. (1975). Test anxiety, attention and the general problem of anxiety. In C. D. Spielberger, \& I. G. Sarason (Eds.), Stress and anxiety. Washington DC: Hemisphere.

Sarason, S. B., Davidson, K. S., \& Lighthall, F. F. (1960). Anxiety in elementary school children. New York: Wiley.

Schwartz, A., \& Schwartz, R. (1993). Depression: Theories \& treatments. New York: Columbia University Press.

Spielberger, C. D., \& Vagg, R. P. (1995). Test anxiety. Bristol: Taylor \& Francis.

Spielberger, C. D. (1980). The test anxiety inventory. Palo Alto, CA: Consulting Psychologist Press Inc.

Spielberger, C. D., Gorsuch, R. L., \& Lushene, R. E. (1970). STAI manual. Palo Alto: Consulting Psychologists Press Inc.

Stuart, J., Rupke, M. D., David Blecke, M., Div, M. S. W., \& Majorie Renfrow, M. D. (2006). Cognitive therapy for depression. American Family Physician, 73, 83-86.

Sultanoff, B., \& Zalaquett, C. (2000). Relaxation therapies. In D. Novey (Ed.), Clinician's complete reference to complementary \& alternative Medicine (pp. 114-129). New York: Mosby.

Tooransposhti, M. G. (2011). A new approach for test anxiety treatment, academic achievement and met cognition. International Journal of Information and Education Technology, 1, 221-229.

Wampold, B. E., Mnami, T., Baskin, T. W., \& Callen Tiemey, S. (2002). A meta-(re) analysis of the effects of cognitive therapy versus "other therapies" for depression. Journal of affective disorders, 68, 159-165. doi:10.1016/S0165-0327(00)00287-1

Wetzel, J. W. (1984). Clinical handbook of depression. New York: Gardner Press.

Zeidner, M. (1998). Test anxiety: The state of the Art. New York: Plenum. 